\title{
POR UMA EDUCAÇÃO VIVA: A ÉTICA DO CUIDADO [ETHICS OF CARE] COMO HORIZONTE DO ETHOS ESCOLAR
}

\author{
Jaderson Silva'
}

\section{RESUMO}

Nos últimos anos, o Ensino de Filosofia no Brasil tem sofrido um descredenciamento por parte de membros da sociedade civil, assim como por membros das instituições públicas. As justificativas centrais têm sido as de que a filosofia não contribui para a formação social e cidadã dos estudantes, ainda menos ao currículo escolar distribuído em disciplinas. Sob tais justificativas, não haveria por que financiar cursos de filosofia (e outras áreas das humanas) com dinheiro público. O presente texto visa apresentar algumas razões, bem conhecidas entre os teóricos da educação em filosofia, de como a filosofia e o seu aspecto transversal assegura a permanência e necessidade da filosofia como parte fundamental do contexto escolar. De modo a diversificar o aspecto transversal da filosofia, apresentamos a ética do cuidado como uma teoria da filosofia moral capaz de se estender para além dos conteúdos das aulas e englobar o mundo da vida dos estudantes. Para isso, apresentamos um breve diagnóstico da situação atual do Ensino de Filosofia no Brasil, as condições da transversalidade da disciplina de filosofia, além de uma caracterização em linhas gerais do que seria a ética do cuidado e como ela poderia contribuir para a aprendizagem dos estudantes.

Palavras-chave: Ensino. Filosofia. Transversalidade. Ética. Cuidado.

\begin{abstract}
In recent years, the Teaching of Philosophy in Brazil has suffered disqualification by members of civil society, as well as by members of public institutions. The central justifications have been that philosophy does not contribute to students' social and citizenship formation, even less to the school curriculum distributed in subjects. Under such justifications, there would be no reason to finance courses in philosophy (and other areas of the humanities) with public money. This text aims to present some reasons, well known among philosophy education theorists, of how philosophy and its transversal aspect ensures the permanence and necessity of philosophy as a fundamental part of the school context. In order to diversify the transversal aspect of philosophy, we present the ethics of care as a theory of moral philosophy capable of extending beyond the contents of the classes and encompassing the students' world of life. To this end, we present a brief diagnosis of the current situation of Philosophy Teaching in Brazil, the conditions for the transversality of the discipline of philosophy, in addition to a characterization in general lines of what would be the ethics of care and how it could contribute to the learning of students.
\end{abstract}

Keywords: Teaching. Philosophy. Transversality. Ethics. Care.

1 Mestrando em Filosofia na Universidade Federal do Rio Grande do Sul (UFRGS). Email: jaderson_tricolor@hotmail.com 
Thaumazein, Ano IX, v. 13, n. 25, Santa Maria, p. 111-123, 2020.

\section{CONSIDERAÇÕES PRELIMINARES}

A educação (Pädagogik) é a arte de tornar as pessoas em seres éticos: ela considera os seres humanos como seres naturais e mostra a eles o caminho para o renascimento, [ou seja,] como a primeira natureza pode ser transformada em uma segunda natureza, espiritual, de modo que essa espiritualidade venha a ser um hábito. (HEGEL, G. W. F. Grundlinien der Philosophie des Rechts, §151 Z). ${ }^{2}$

Passado um pouco mais de uma década do retorno da filosofia e da sociologia como disciplinas obrigatórias do ensino básico, encontramo-nos uma vez mais em um cenário que tende antes para a retirada de tais disciplinas do currículo escolar ao invés do incentivo necessário, seja este institucional ou não, que garanta a permanência dessas disciplinas, uma vez reconhecidas como áreas fundamentais à toda formação educacional e cidadã. Não seriam poucas as ameaças de desarticulação e redução de oportunidades de ensino que as disciplinas de filosofia e de sociologia têm recebido por parte de alguns grupos com poder econômico e outros com poder político, isto é, de membros da sociedade civil e membros das instituições brasileiras. ${ }^{3}$ Assim, parece que a filosofia no Brasil tem se alinhado ainda mais à tradição proveniente da Europa, não pelo seu conteúdo - evidentemente, de muita qualidade e valor -, mas pelo seu caráter externo: as perseguições e descredenciamentos à filosofia como ocorreram em diversas épocas e lugares por onde ela passou e teve influência no modo de vida dos cidadãos.

Nesse novo cenário da educação brasileira existem ainda - entre os detratores - aqueles que prezam por certa dignidade da disciplina de filosofia, contanto que esta seja desenraizada de correntes filosóficas tradicionalmente conhecidas pelo Ocidente e adquira novas conotações, mais utilitárias e motivacionais, assim como menos distante do "real interesse" do cidadão (de bem) e pagador de impostos. Apesar de menos presentes nas notícias das grandes mídias, já há alguns anos a filosofia vem sendo cooptada por adeptos do coaching e de práticas semelhantes com o intuito de resgatar a noção de filosofia como uma atividade da vida. No entanto, seguramente podemos afirmar que nesse contexto existe a desconsideração plena da relação que a filosofia como atividade carrega diante da formação cultural e cidadã de adolescentes e jovens na educação básica. Notadamente, a instrumentalização da filosofia

2 No original: "Die Pädagogik ist die Kunst, die Menschen sittlich zu machen: sie betrachtet den Menschen als natürlich und zeigt den Weg, ihn wiederzugebären, seine erste Natur zu einer zweiten geistigen umzuwandeln, so daß dieses Geistige in ihm zur Gewohnheit wird".

3 A quem ainda duvidar, basta uma rápida pesquisa no Google através de palavras como "ministério da educação - filosofia - investimento público" para então encontrar algumas tantas matérias de jornais, artigos científicos e discursos públicos de membros do governo federal problematizando a existência do Ensino de Filosofia. A respeito deste último, há um vídeo no Youtube em que um atual ex-ministro da educação declara abertamente a suposta necessidade de repassar os investimentos das áreas de cursos de elite, como o de filosofia, para áreas como aquelas das Engenharias e Saúde. Tomando o suposto modelo japonês como exemplo, o ex-ministro afirma que podemos estudar filosofia, desde que seja "com o dinheiro próprio" ("Estudar Filosofia só com dinheiro próprio, diz ministro da Educação", 2019, 1m48segs). Em uma entrevista ao UOL, também disponível no Youtube, o mesmo ex-ministro reafirma: "com o dinheiro que eu pago imposto, eu quero mais médico e mais enfermeiro. Se o cara quer fazer filosofia, vai fazer com o dinheiro dele. Meu filho pode fazer filosofia? Lógico que pode. 'Papai, eu quero fazer filosofia!. 'Filhão, você já está trabalhando?'”('Weintraub diz que não quer mais sociólogo, antropólogo e filósofo com dinheiro público", 2020, 42segs). 
para fins motivacionais acarreta em uma diluição da especificidade desse saber humano no que tange ao seu aspecto de transmissão dos questionamentos tradicionais e basilares do pensamento ocidental em toda sua diversidade, assim como reforça o espírito individualista incapaz de manter em perspectiva a responsabilidade do sujeito em relação aos outros e ao mundo em seu entorno.

Por outro lado, o que pode nos causar um maior estranhamento é o fato de encontrarmos não somente do lado de lá um enfraquecimento da importância do Ensino de Filosofia no país, mas igualmente depararmo-nos com semelhantes justificativas do lado de cá do campo teórico-institucional. ${ }^{4}$ Sob a alegação de falta de boas razões para a continuidade da obrigatoriedade da filosofia no ensino básico, em especial no ensino médio, por vezes somos lançados à perspectiva de que nem mesmo enquanto disciplina de formação haveria qualquer especificidade no trabalho do filósofo ou da filósofa. Estes exerceriam um papel facilmente substituível por outras áreas, de modo que, na nossa constante defesa de permanência da filosofia no ensino médio, não teríamos razões, senão paixões, que nos motivam a prestar solidariedade aos professores e às professoras.

Não obstante, o autor parece estar correto ao declarar que, se nosso critério é unicamente a formação da consciência crítica, então outras disciplinas e áreas do saber humano exerceriam um papel mais eficaz nesse propósito. Ele elenca, a título de exemplo, o Direito e a Música como prováveis substitutos da filosofia no ensino médio e dignos de atenção dos jovens e adolescentes em sua formação, sendo o primeiro destinado à consciência cidadã (o estudo da Constituição e seu potencial legal) e o último à consciência histórico-cultural (o estudo dos clássicos de dentro e fora do país). Contudo, mesmo que reconheçamos essa alternativa como viável, em um panorama de discussões a respeito do Ensino de Filosofia no Brasil, permanecem algumas questões centrais em aberto: a formação de consciência crítica é o critério principal para o Ensino de Filosofia obrigatório em todo o país? Esse tópico esgota o conjunto de discussões e intenções dos professores (as) de filosofia? Não haveriam outras alternativas e pressupostos legitimando a preservação de uma disciplina que, em diferentes épocas e lugares, tem sido atacada e perseguida?

Antes mesmo da publicação dessas teses da insustentabilidade da filosofia enquanto disciplina obrigatória no currículo escolar, Ronai Rocha (2015) em seu livro Ensino de Filosofia e Currículo havia tratado da problemática em torno da hipótese de que o papel de professor (a) de filosofia consistiria exclusivamente em formar uma consciência crítica nos estudantes. Segundo este autor, quando nos voltamos para alguns documentos oficiais tratando das orientações de cada disciplina componente do currículo escolar, fica evidente o elemento comum de disciplinas formadoras de consciência e cidadania. Nesse sentido, falar em "consciência" ou "consciência crítica" seria muito mais um recurso discursivo sem exposição de metodologia especificada para isso do que uma habilidade transmitida apenas pela filosofia. Longe de concluir com a dispensabilidade dos (as) filósofos (as) da escola, Ronai indica uma das primeiras razões de por que a filosofia deve ser concebida como disciplina fundamental de um currículo escolar distribuído organicamente, isto é, onde cada disciplina pode ser justificada tanto por sua habilidade ou competência específica, quanto em relação às outras disciplinas em diálogo com ela. De acordo com o autor, as disciplinas como História, Português, Biologia, entre outras, contribuem para a determinação da especificidade da filosofia e, com isso,

4 Refiro-me ao texto "Por que não defendo a obrigatoriedade da Filosofia no Ensino Médio" (2016), de João Vergílio Gallerani Cuter, publicado na Coluna ANPOF. Disponível em: https://bit.ly/3kyvh6p. 
Thaumazein, Ano IX, v. 13, n. 25, Santa Maria, p. 111-123, 2020.

(...) pedem ao professor de Filosofia que faça sua parte específica, por exemplo, ajudando o aluno a ter consciência a respeito da estrutura da argumentação apresentada em suas escritas e leituras, quaisquer que sejam (ROCHA, 2015, grifo nosso, p. 61).

Nessa perspectiva, tratar da estrutura argumentativa de um texto é um exercício por meio do qual podemos ler com maior precisão tanto textos filosóficos quanto textos de outras disciplinas presentes na vida escolar dos estudantes. A filosofia, portanto, portaria um método versátil em seu procedimento. Contudo, se, por um lado, o treinamento das habilidades argumentativas estabelece a especificidade da filosofia em relação ao contexto escolar, com tal característica, por outro lado, a filosofia se afirma como a disciplina dotada da transversalidade 5 latente no currículo escolar em geral. Ou seja, fica a cargo da filosofia, em função de sua especificidade na relação com as outras disciplinas do currículo, a explicitação da transversalidade pensada na constituição das disciplinas do ensino básico, embora tal aspecto transversal tenha sido muito pouco executado na prática docente.

Afinal de contas, o saber filosófico reúne em si as habilidades e metodologias mais apropriadas para lidar com problemas complexos das ciências em geral, desde a comparação de paradigmas até a definição de termos caros à prática científica conforme sua historicidade conceitual. ${ }^{6}$ Por certo, as discussões filosóficas podem assentar em questões que desdenham o conhecimento empírico, porém, temos de reconhecer que as habilidades argumentativas utilizadas em qualquer fundamentação teórica são frutos de costumes e práticas humanas desempenhadas nesse mundo. Com isso, queremos dizer que conceber a peculiaridade da filosofia segundo o exercício de habilidades argumentativas não significa que a disciplina seja meramente formal, como se poderia pensar apressadamente, mas isso também tem de significar que ela carrega sempre uma dimensão mundana e concreta, resultado das dinâmicas linguísticas e sociais de um período.

Cabe destacar aqui o interesse de alguns teóricos da educação em filosofia com a ideia de transversalidade como um ponto de manifestação da organicidade do currículo escolar. A transversalidade da filosofia, no que lhe diz respeito, lentamente, vem ganhando concretude em instituições de ensino. ${ }^{7}$ Sílvio Gallo e Américo Grisotto (2002), além de Ronai Rocha (2017), destacam a importância da interdisciplinaridade 5 Do latim transversare, onde a preposição trans significa "através de" ou "para o outro lado de" e o verbo versare tem o sentido de "virar/girar algo" ou "movimentar-se a alguma direção", como na palavra "versátil", cujo significado consiste em "aquele que se desloca de uma posição à outra com facilidade". Assim, "transversalidade" expressa a possibilidade de envolver diferentes tipos de saberes na análise de um objeto. Quando aplicado à educação e ao ensino de filosofia, entendemos a transversalidade como um atravessamento das fronteiras que separam cada tipo de curiosidade humana ou, metaforicamente, um caminho/passeio por entre as disciplinas escolares de modo a apresentar diferentes perspectivas acerca de um mesmo problema. Vale ressaltar que o aspecto específico de cada disciplina deve ser preservado, pois por meio deste aspecto que as disciplinas asseguram seu traço transversal.

60 que os cientistas têm entendido por "fenômeno", quando falam em "fenômeno natural"? A noção de "natureza" sempre foi esta que compreendemos hoje? Podem duas teorias científicas coexistir a partir de modelos interpretativos distintos?

7 Penso aqui nos cursos preparatórios para vestibular e os seus famosos "Aulões de sábado". Nesse evento, busca-se tratar de um único tema ou acontecimento natural ou social à luz de diferentes disciplinas. A intenção é a de que a complexidade do problema tratado seja evidenciada aos estudantes e estes tenham a experiência com o aspecto relacional de cada disciplina, não somente visando a realização da prova de ENEM ou Vestibular, mas também resgatando a relevância de uma formação científico-cultural. Até onde eu sei, com os cursos populares têm sido assim. 
para uma análise mais concreta da complexidade de alguns aspectos da realidade que excedem o escopo de uma disciplina em particular.

A ênfase em uma prática didática tem o objetivo de combater o isolamento das disciplinas e da falta de comunicação entre os (as) professores (as) de diferentes áreas a respeito dos seus conteúdos. Nesse sentido, a transversalidade teria duas vantagens no aprendizado dos estudantes: de um lado, assegura a interdisciplinaridade capaz de manifestar a organicidade subjazendo o planejamento curricular. Essa visão orgânica da unidade escolar permite ao estudante o acompanhamento de análises de fenômenos da realidade com mais precisão e clareza. Por outro lado, como uma consequência dessa primeira vantagem, a transversalidade também proporciona ao estudante uma espécie de "força criadora" (GALLO; GRISOTTO, 2002, p. 65) na medida em que possibilita o rompimento da formatação rígida das disciplinas a um novo patamar no qual todo saber atingido pode ser tomado como um saber produzido entre professores (as) e estudantes conjuntamente. Ou seja, toda atitude interdisciplinar no contexto escolar carrega um elemento de inovação dos saberes, contanto que não sobreponha a especificidade de uma área à especificidade de outra. Como um resultado do que temos visto até aqui, portanto, podemos afirmar a existência de um espectro rondando o Ensino de Filosofia no Brasil - o espectro da transversalidade.

Esses e outros fenômenos sociais têm estado em contato direto com a possibilidade do Ensino de Filosofia e configuram um conjunto suficiente - mas de modo algum, exaustivo - de problemas exteriores e abrangentes perturbando o desenvolvimento de planos e propostas até então discutidas sobre a relevância e o mérito da filosofia como parte constituinte das unidades escolares no território brasileiro. Destacar a transversalidade da disciplina de filosofia no currículo escolar significa defender a presença desta curiosidade humana - e mesmo da sociologia - como disciplina (s) obrigatória (s) nas escolas de nível médio. À vista disso, na educação básica a filosofia consistiria realmente em uma atividade, embora muito diferente do que é pensado em práticas ordinárias e utilitárias, pois seria a atividade da suspensão dos juízos comuns visando o uso de conceitos adequados a determinado contexto. Com isso, podemos indagar: qual é o nosso atual contexto escolar? Que tipo de dinâmica social este contexto tem apresentado aos estudantes?

\section{QUAL É O NOSSO ETHOS ESCOLAR?}

Para além da interpretação utilitária do contexto escolar como um espaço de instrução para o mercado de trabalho, esse espaço representa, senão o primeiro, um dos primeiros ambientes em que o estudante pertence a uma comunidade orientada não mais pela hierarquia e obediência familiar, mas por um conjunto de regras universais que recaem sob pessoas de diferentes famílias e costumes. O ambiente da educação não se limita a um espaço de instruções de técnicas e macetes onde se aprende o conteúdo à exceção do mundo da vida. Essa interpretação é meramente mecânica. Antes de mais, a educação é viva e permeada pelo constante movimento de diferentes perspectivas orientadas por um objetivo comum, a saber, a formação integral como pessoa e cidadã. Neste lugar, a responsabilidade individual experimentada no âmbito familiar deve ser substituída pela responsabilidade coletiva e tornada consciente aos membros para que estes, na medida do 
tempo, não confundam o novo ambiente com o anterior. ${ }^{8}$ Doravante, temos de tratar da dinâmica interna às escolas do Brasil. Por onde começar?

A relação entre o (a) professor (a) ou funcionário (a) da escola e o estudante não diz respeito ao aspecto natural da vida, mas à ética inerente ao convívio social, ainda que nos anos iniciais seja bastante comum o chamamento de "tio" e de "tia" por parte das crianças. Assim, sem dúvidas, existe um ethos subjazendo as relações travadas no contexto escolar, seja na relação entre adulto e adolescente ou na relação entre colegas. A cada geração surgem novos desafios e práticas sociais em vista, sendo muito improvável que as dinâmicas escolares não se alterem diante dessas inovações. De modo a levar isso em consideração, podemos muito brevemente nos ater a dois fenômenos sociais coexistentes na lógica interna escolar atual: o Programa Escola sem Partido e a Cultura do Cancelamento.

O Projeto de Lei n. ${ }^{\circ}$ 246/19, tratante do Programa Escola sem Partido em sua versão 2.0, visa à manutenção e ao maior controle do que se passa dentro das escolas brasileiras, assim como da relação dessas com os movimentos políticos e sociais que compõem a esfera pública do país. Segundo seus defensores, o projeto assegura que os estudantes e as convicções herdadas de suas respectivas famílias não sejam impedidos de manifestação pública na escola por professores (as) ou funcionários (as) da escola e nem que estes doutrinem seus (as) alunos (as) com conteúdos e ensinamentos de cunho religioso, político ou moral contrário aqueles da família do estudante. O impacto desse projeto recai diretamente nessa distinção entre a comunidade familiar e a comunidade escolar, no sentido de que contribui muito mais para o obscurecimento dessa linha tênue do que para o reconhecimento do papel de ambos os contextos no tocante à educação moral dos estudantes. Em seu mais recente livro, Ronai Rocha ("Escola partida: ética e política na sala de aula", 2020) procura analisar em que consiste essa disputa social e política e qual seu potencial para o mundo da vida dos adolescentes. O autor afirma o seguinte no que parece ser o núcleo de sua interpretação desse projeto de lei: "(...) não é razoável negar que a escola é, em certas condições e sob um certo ponto de vista, um lugar de disputas políticas e sociais", mas disso não se segue que ela seja "um espaço de ação política em primeiro lugar" (ROCHA, 2020, p. 91). Para interpretações apressadas, isso poderia soar contraditório, manifestando um "sim" e um "não" ao papel político dos membros da escola. Contudo, devemos observar que, como o autor tem procurado mostrar, a razão de ser da escola não é a de um espaço de resolução de problemas políticos e sociais presente no mundo dos adultos, ${ }^{9}$ mas é inegável que, por ser uma instituição da sociedade, ela também deve ser apreciada política e socialmente. Seria ingenuidade de nossa parte considerar a escola à parte da esfera pública.

Em outras palavras, a escola é um espaço privilegiado da transmissão de conhecimento herdado das gerações anteriores, na qual, por vezes, manifestam-se como efeitos dessa herança, e não como causas de tal, o envolvimento com problemas de cunho religioso, moral e político do mundo concreto. Como um espaço de formação da consciência cidadã, devemos esperar estudantes manifestando-se politicamente, assim como indagando convicções alheias e as suas próprias. O problema reside na ilusão

8 É curioso como essa dinâmica é bastante semelhante à dinâmica da transversalidade da filosofia, na medida em que há o deslocamento da singularidade a outras particularidades sem perder a sua identidade própria.

9 Esse elemento tem-se manifestado em alguns cursos de graduação em licenciatura que concebem a educação exclusivamente como um ato político e esquecem-se do papel pedagógico a ser desempenhado. Por certo, aqui estamos falando de raras exceções. 
de que um estudante não possa conscientemente perceber-se mais respeitado por seus (as) professores (as) e a eles (as) destinar sua educação moral ao invés do que aos seus pais que não o escutam ou buscam tomar conhecimento de suas preocupações específicas enquanto um jovem dotado de dilemas morais. ${ }^{10}$

De outra parte, tem-se constituído nos hábitos e costumes de quase todos os jovens e adolescentes dos dias atuais o uso de redes sociais virtuais (aplicativos ou sites de relacionamento). Um fenômeno que tem chamado a atenção não só dos usuários comuns, mas também daqueles com olhares mais críticos, é o do cancelamento virtual. Pode parecer à primeira vista inofensivo, e mesmo cômico, abordar tal comportamento de usuários em redes sociais, mas pensando no fato de que esses usuários que diariamente utilizam tais redes são, por um lado, os adultos juridicamente responsáveis por suas atitudes e, por outro, crianças, adolescentes e jovens que mantém uma rotina entre a casa e a escola, parece-nos que esse fenômeno social entra em conflito com a concepção comunitária, de diversidade cultural e de respeito mútuo transmitida pelas escolas brasileiras. Em que se assentam tais cancelamentos? Na prática persecutória de figuras públicas (ou não) com o intuito de denunciar suas publicações antigas ou atuais em que estas pessoas tenham incorrido em alguma forma de preconceito ou ofensa a qualquer grupo social, seja ele minoritário ou não. Em outros termos, tal prática retoma costumes antigos de afastar da coletividade todo sujeito que tiver um comportamento estranho à comunidade, mesmo que por algum equívoco momentâneo de sua parte."

Se a escola é um ambiente extrafamiliar no qual entramos em contato com pessoas de diferentes lugares e com diferentes costumes, as redes sociais e o que lá acontece também influenciam na formação da consciência social e política dos estudantes. Ou seja, o conflito entre esses dois ambientes é inevitável. O que aqui entra em jogo é a fragilidade das relações socioafetivas das crianças e dos adolescentes ao terem de lidar com questões envolvendo o bem comum e o respeito mútuo na comunidade escolar, ao mesmo tempo em que o extremo oposto em seu outro espaço de convívio social, ainda que virtual. Ou mesmo pior, é muito provável acontecer de ser vítima de tal "cancelamento" por partes de colegas no âmbito escolar, onde justamente os valores voltados para a diversidade cultural e o respeito entre os pares deveriam ser exercidos. Sem dúvidas, poderíamos optar por esconder essa dinâmica social-virtual dos mais novos, mas nos perguntamos: por quê? Por que acobertar um tipo de comportamento do qual, cedo ou tarde, o estudante pode ser vítima?

Ao que tudo indica, os dois fenômenos sociais aqui apresentados encontram um ponto de contato de acordo com suas feições punitivistas e individualizantes, de modo a expressar perturbações ao livre reconhecimento das intersubjetividades que sustentam o convívio social, dentro e fora da escola. O caso de um (a) professor (a) que apresenta uma lista ampla de correntes políticas ocidentais aos seus (as) alunos (as) e é acusado de doutrinação ideológica e partidária por não ter restringido sua aula ao único movimento político que interessava ao governo da época ou um sujeito (se quisermos, alguém em formação escolar) que manifestou seu ponto de vista provisório ainda sem muito conhecimento do assunto

10 A este respeito, Ronai é preciso ao perguntar se “(..) seria demais lembrar aqui que a relação entre os professores e as crianças nunca é isenta de sentimentos e valores morais? (...) Que a educação moral começa no 'bom dia' que nos dão ou não e termina, no outro dia, na forma como nossa mãe nos consola dos pesadelos que tivemos à noite?" (ROCHA, 2020, p. 140). 11 Para uma excelente e concisa análise desse fenômeno, confira o texto de Filipe Campello (UFP), publicado na Coluna ANPOF e intitulado "Paradoxos dos cancelamentos" (2020). 
a um público extenso e recebeu uma série de ofensas e ameaças sem direito à retratação, certamente, são demonstrações de um ethos que se limita a punições e a rejeições de toda e qualquer alteridade. ${ }^{12}$ Esse é o horizonte que esperamos atingir junto aos recém-chegados ao mundo? Podemos assegurar uma experiência educacional tranquila e criativa diante disso? Somado à feição punitivista, há também a individualização por meio da culpa que retira, como se fossemos descartáveis, o (a) professor (a) de sua comunidade escolar (psicológica e literalmente) ou mesmo o usuário das redes sociais do único espaço de interação com outras pessoas que não sejam apenas amigos e familiares. Essa consciência individualizante elimina a possibilidade de espaços de deliberação na sociedade que independam desta ou daquela instituição pública e acaba por reforçar a síndrome de $1 t^{13}$ que há um longo tempo tem estado presente na esfera social.

Na consideração do papel da transversalidade da filosofia na aprendizagem dos estudantes do ensino básico, Sílvio Gallo e Américo Grisotto (2002) propõem a área de ética como aquela mais apropriada ao exercício do aspecto transversal na escola, pois, se no processo de aprendizagem devemos considerar a formação dos estudantes também enquanto cidadãos livres e iguais, então subjacente a isso deve haver ferramentas e conceitos-chave que dizem respeito à ética e à filosofia moral. A proposta é a de que pensemos "o aprendizado ético de fato, transversalizado na escola" (GALLO; GRISOTTO, 2002, p. 65). Como temos afirmado acima, a transversalidade da filosofia também assegura aos estudantes uma maior aprendizagem das outras disciplinas..$^{14}$ Aceito que estamos lidando com fenômenos sociais carregados de problemas éticos que atravancam o aprendizado dos estudantes em um ambiente saudável e pacífico, possivelmente, nesse momento a contribuição mais oportuna da filosofia e de seu aspecto transversal pode ser encontrada em suas lições de ética.

Ora, mais uma vez parece que encontramos a necessidade da filosofia no currículo escolar, pois, qual disciplina senão a filosofia para evidenciar o fato de que somos seres que vivem em comunidade, seja natural ou social. Segundo a hipótese aqui defendida, a área de ética parece ser aquela mais adequada para tratar dos temas embaraçosos que atravessam a vida cotidiana e a formação escolar dos estudantes. Questões como "como devemos viver?", "como podemos autonomamente escolher alguma coisa?", "o que significa a liberdade?", entre outras, caracterizam inquietações filosóficas presentes não apenas nos manuais escolares, mas igualmente na vida de cada estudante. A seguir, propomo-nos a apresentar uma teoria ética muito pouco ou quase nada abordada nas lições e manuais de ética de

12 Diante disso, a filosofia parece estar adiantada: "(...) Se eu seguir as leis pelo simples medo da punição, estou agindo forma heterônoma, respeitando as normas por uma motivação externa. Mas se ajo de forma ética, não por medo das punições, mas por que estou convencido das razões pelas quais é certo fazer, então estou agindo de forma autônoma, cumprindo as normas por uma motivação interna. (...) Agora, imagine alguém que cumpre as normas simplesmente porque entendeu a importância de cumpri-las; nesse caso, há uma motivação interna, a sua própria consciência é a causa dessa ação" (PEREIRA, 2013, p. 191).

13 Refiro-me aqui ao longa-metragem It (2017), inspirado na produção literária de Stephen King de 1986. O poder que o personagem Pennywise exerce sobre as suas vítimas serve como boa metáfora a um modo de vida caracterizado pelo medo, culpa e angústia, impossibilitado de perceber a comunidade a que pertence e coabita com outras pessoas que podem acolhê-lo. Ao longo do filme, notamos que o principal objetivo do palhaço assassino é desunir aqueles que o enfrentam para assim enfraquecê-los. 14 A propósito disso, Ronai Rocha (2015) afirma que “(...) a criança [e, igualmente, o adolescente e o jovem] não se sai melhor nos cálculos por ter esta ou aquela concepção sobre a natureza dos números, mas poderá ter suas experiências de aprendizado enriquecidas se o currículo the oferecer este espaço de razões e argumentos sobre conceitos fundamentais" (p. 44). 
Ensino de Filosofia no Brasil. A opção por tal teoria, no entanto, repousa sob a interpretação de que para respondermos às atuais ameaças ao Ensino de Filosofia, temos de resgatar pressupostos dessa disciplina que garantam sua relação íntima com o mundo concreto e com a vida daqueles a quem a escola se destina, isto é, aos estudantes. Portanto, no contexto atual a teoria que parece estar no horizonte do ensino de filosofia moral nas escolas é a ética do cuidado.

\section{A ÉTICA DO CUIDADO COMO HORIZONTE}

Decerto, existem muitas teses ao longo da tradição do pensamento ético ocidental capacitadas para fornecer uma interpretação bastante concreta e precisa dos laços sociais que mantemos em relação aos outros durante toda nossa vida. A ética tem a vantagem de incorporar temas e problematizações nos quais, certamente, todas as pessoas já questionaram na sua experiência de pensamento em algum momento. O papel atribuído à área de ética e filosofia moral carrega o peso de pôr em evidência o fato de vivermos sob normas e regras de conduta pensadas em vista do maior número de pessoas e, por isso, haver uma disputa entre as diferentes doutrinas éticas quanto as suas plausibilidades. Ao retomarmos as escolas éticas clássicas nada nos impede de ainda encontrar aspectos da realidade que encarnam tais teses. No entanto, com o intuito de explicitar a especificidade das questões contemporâneas que atravessam as dinâmicas sociais até aqui abordadas, optamos por apresentar de modo geral única e exclusivamente a ética do cuidado.

As indicações do atual contexto do Ensino de Filosofia reverberam numa interpretação da filosofia e do filosofar bastante exterior. Através desse descredenciamento, a filosofia, em especial a ética, vem sendo apropriada por discursos tecnocratas como uma disciplina "da civilidade" e do "respeito à ordem e as leis". 15 Essa é uma interpretação bastante limitada e heterônoma para uma ética que se pretende universalmente válida. A ética está sendo concebida, nessas circunstâncias, como um conjunto de regras que nos dizem como devemos nos comportar em sociedade, sem antes nos assegurar as condições para agirmos autonomamente sem a negligência da liberdade e do convívio democrático. Ou seja, nesses casos a ética seria meramente uma lista de regras que devemos nos adequar, a despeito de qualquer motivação interna anterior ao nosso comportamento. Além disso, a adequação individual parece antes manifestar uma reação à imposição externa oriunda da força e da obediência à uma hierarquia pré-estabelecida e de índole militar. Em tempos de crises democráticas, há quem faça o elogio dessas características.

Na contraposição de qualquer forma de hierarquização da ideia de respeito, a ética do cuidado surge como uma doutrina ética contemporânea consistindo na ênfase das relações de cuidado e interpessoais presentes na experiência humana. Acredita-se que algumas teorias éticas tradicionais tiveram desdobramentos em épocas específicas que acarretaram no fato de dar margem a questões heterônomas que escapam ao interesse intersubjetivo. A ética do cuidado se propõe como uma revisão da teoria moral clássica. O cuidado, portanto, ressurge no debate de teoria moral para destacar o fato de que não somos pessoas plenamente autossuficientes e independentes de nossos laços sociais. O reconhecimento do papel desempenhado pelo amor e o cuidado na teoria moral mostra que o bem comum e a justiça

15 No tocante a esse tema bastante relacionado à educação brasileira, confira o texto "Não se pode educar sem convicções" (2018) de José Sérgio Fonseca de Carvalho, publicado no site Nova Escola. 
não são categorias morais que regem sob indivíduos atomizados, porém, são categorias comunitárias e intersubjetivas (reelaboradas em conformidade com o sensus communis) que expressam a rede de relações humanas. Desse modo, tais valores comunitários podem ser concebidos não mais de um ponto de vista heterônomo, mas agora alicerçados sob a base de princípios dinâmicos de autonomia e confiança nos outros.

Por que o "cuidado" seria aqui o conceito-chave? No conjunto das doutrinas éticas clássicas, haviam como pressupostos comuns as distinções entre leis universais e leis específicas, mundo objetivo e mundo subjetivo, neutralidade e pessoalidade, imparcialidade e parcialidade, aqueles que são racionais e os outros apenas emocionais. Tais dicotomias reforçavam a ideia de que uns têm fatos enquanto outros têm meras opiniões, de modo a deslegitimar qualquer discurso contrário ao que se tinha por convenção. A ética do cuidado, contraposta às éticas das leis, procura combater essas falsas dicotomias, apresentando a dimensão de unidade desses conceitos diferentes. Para tomar um caso, a noção clássica de "razão" oposta à "emoção" pode ser reformulada de um modo mais concreto quando observamos a dinâmica das ações éticas. Poucas pessoas ainda estariam dispostas a negar que o sentimento moral contribui para execução da racionalidade na tomada de decisões em casos-limites. ${ }^{16}$ Isto significa que, diferente do que foi pensado por muitos autores clássicos, existe um papel cognitivo das emoções que deve ser levado em consideração na teorização do fenômeno ético. Aqui, o cuidado exerceria essa transposição de uma dinâmica que poderia ser apenas uma atitude natural para uma perspectiva mais racional.

A palavra "cuidado" vem do latim coera, como cura ou mostrar preocupação, o que nos remete à atenciosidade e acolhimento. Entretanto, também podemos mapear sua raiz etimológica na palavra latina cogitare, que significa refletir ou pensar. Desse modo, o "cuidado" porta o duplo sentido de exprimir uma relação de afeto quanto uma atitude racional. Em vista disso, Virginia Held (1990) fala da experiência da maternidade (mothering), concebido como um fenômeno que diz respeito a todos os gêneros e não exclusivamente ao feminino, de acordo com a tese de que aí igualmente teríamos um conceito importante para a teoria moral, mas que a teoria clássica havia rejeitado. Os cuidados maternais, diferente do que se passa com os animais, pode ser apreciado deliberativamente, pois consiste em uma de nossas fontes da noção de "importar-se com" que as obrigações éticas nos proporcionam nas relações entre nós e os outros. Nesse sentido, a ética do cuidado evoca, antes de mais, a importância da interpessoalidade na dinâmica da vida ética, em detrimento da postulada impessoalidade presente nas éticas das leis.

Em uma leitura apressada, poderíamos confundir o objetivo da ética do cuidado como o mero ato de distribuir atenção e carinho para os demais, perdendo de vista o seu verdadeiro papel que é o de mostrar a importância das emoções e das paixões na concretude da ação ética. A ênfase no papel das emoções não tem por finalidade descrever as decisões éticas como inteiramente pautadas nas emoções e dependentes das inclinações pessoais, mas visa denunciar as formas elementares dos laços comunais efetivos. Com a imposição de tudo o que não é racional ao privado e ao feminino, a ética ou teoria moral perdeu parte de suas categorias morais para uma compreensão integral das ações éticas em sociedade. No entanto, de modo algum isso quer dizer que as mulheres são apenas restritas a sentimentos e afetos, sendo a ética do cuidado o meio teórico mais adequado a essa característica especificamente feminina.

16 o bem conhecido dilema moral do trem descontrolado em que temos de decidir pela vida de alguém da nossa intimidade ou um conjunto de pessoas inocentes pode iluminar esse ponto. 
O que ocorre é que, com a desconsideração de parte da humanidade na definição do que é ser ético, também foram excluídas algumas das categorias necessárias para a compreensão da experiência concreta dos seres humanos, como aquelas que explicitam o fato de que questões racionais mantêm íntima relação com questões emocionais ou fruto das paixões humanas. Por conseguinte, devemos distinguir entre aquilo que é natural (como a diversidade dos sexos) e aquilo que é cultural (produto das condições de cada época e território). Assim, essa doutrina procura reabilitar as categorias morais que dizem respeito a todos os gêneros humanos.

Longe de ser uma ética reativa, a ética do cuidado coloca-se como aquela capaz de reabilitar as potencialidades éticas perdidas ao longo do pensamento ético ocidental. Ao lançarmos os olhos para o mundo grego, somos capazes de vislumbrar naquela atitude desobediente de Antígona diante do seu tio e rei Creonte um dos potenciais éticos menosprezados por parte da tradição filosófica. Por assim dizer, se ao sepultar seu irmão Antígona propunha indiretamente uma reconfiguração das leis da cidade e do autoritarismo vigente, por outro lado, essa personagem de Sófocles expressa a importância da consideração de valores interpessoais nas nossas tomadas de decisões em dilemas morais. Vejamos a passagem a seguir dessa tragédia grega:

“(...) Creonte: no entanto, as pessoas boas anseiam por uma porção sem igual às pessoas más. Antígona: quem sabe se essas ações são puras para aqueles que estão abaixo de nós?

Creonte: você não ama alguém que você odiou, nem mesmo depois da morte.

Antígona: não é a minha natureza aderir ao ódio, mas antes ao amor.17

Creonte: então, caia ao inferno e os ame, se você assim quiser." (SOPHOCLES, 1891, tradução e ênfase nossa, linha 449)

Dessa maneira, Antígona não é só provavelmente o primeiro símbolo de resistência a um governo autoritário, mas também uma personagem histórica que nos brinda com a possibilidade de uma nova base ético-política. Através do conto ficcional, não temos a sobreposição da consciência individual sobre o Estado e o político, o que determinaria a vitória do oikós sobre o kóinon. Contudo, a atitude de Antígona nos indica uma nova maneira de pensar a dimensão objetiva do ethos próprio da esfera pública. Por conseguinte, à luz do que temos visto, Antígona serve de exemplo de autonomia calcada em motivações internas de duas ordens em união frente à heteronomia executada por Creonte.

Uma vez que o propósito da aplicação da ética do cuidado à educação contemporânea procura resgatar a noção de uma subjetividade que, na verdade, desvela-se intersubjetiva, podemos aqui elencar a descoberta de Piaget a respeito do papel da autonomia na educação moral das crianças e adolescentes. ${ }^{18}$ Jean Piaget reconhecia que, nos primeiros anos de vida, as crianças tendem a internalizar regras morais ditadas pelos adultos e, a partir dessas regras, orientam seus comportamentos e a capacidade de mentiras que podem ser ditas aos outros. Contudo, percebemos que essa característica, embora bastante evidente nos bebês e nas crianças, expressa a tendência humana de, em seu primeiro contato com valores morais, internalizar preceitos de modo totalmente heterônomo. Quando Piaget foi ao Leste Europeu visitar uma instituição de jovens infratores dirigida, segundo acordo dos adultos, por valores de 17 Compreendo a experiência do "amor" como uma forma elementar de comunicabilidade intersubjetiva. 18 Cf. Piaget, 2011, p. 111. 
auto-organização entre os jovens que então ele encontrou dois elementos essenciais para a expressão da autonomia: a responsabilidade e reconhecimento. ${ }^{19}$

É justamente quando percebemos como nossas aquelas regras e valores morais dos adultos. Quando somos responsáveis por acolher outros seres humanos na prática, então vivenciamos a experiência interna de refazer a trajetória das gerações anteriores e, portanto, agimos como se fossemos nós aqueles autores das leis morais, isto é, agimos com a autonomia necessária à vida adulta.

Nesse sentido, o chão da escola (seus limites espaciais) constitui o primeiro laboratório onde podemos refletir, discutir e elaborar em conjunto questões e respostas a respeito do que estamos fazendo durante o intervalo de tempo entre nascimento e morte, ou seja, como existentes em um mundo. No que diz respeito à ética do cuidado e a escola, podemos compreender que o aprendizado dessa ética na disciplina de filosofia tem por objetivo responder aos problemas em aberto pelas teorias clássicas sobre a plausibilidade de leis universais, assim como traçar caminhos tangentes ao comportamento humano em um contexto escolar onde os estudantes devem ser reconhecidos enquanto tais, mas também como estagiários de meio-turno, membros de uma família ou grupo de amigos e, acima de tudo, agentes racionais ingressando na vida adulta. A ética do cuidado não é uma negação da objetividade do conhecimento, mas uma revisão desta e um aprimoramento.

\section{À GUISA DE CONCLUSÃO}

Em tempos de uma pandemia que isola e afasta as pessoas do seu convívio social, além de evidenciar a fragilidade da vida natural apesar de todo avanço tecnológico das últimas décadas. A ética do cuidado pode oferecer um caminho alternativo na medida em que transmite a ideia de solidariedade, resgatada no atual contexto pelos canais institucionais, ao acolher e refletir junto à alteridade. Pensemos na origem da palavra "solidariedade", do latim solidare, como um fundamento ou apoio, que, por sua vez, deriva de solidus (sólido ou consistente). Não é por acaso que a ética do cuidado possa incluir um princípio de solidariedade diante da alteridade, como próprio de uma relação que se inicia entre as pessoas mais próximas e pode se estender a relações potenciais. Essa corrente de pensamento busca justamente retirar a normatividade de princípios abstratos, como justiça imparcial, e reconquistar o sentido mais concreto e mais sólido das normas por trás das nossas relações éticas.

Ainda parece ser cedo demais para um diagnóstico de época contundente. Entretanto, mais do que nunca, questões como o respeito mútuo, o cuidado com a saúde das pessoas mais idosas ou de risco, o isolamento social e etc, retomam a importância da vida ética e da dependência mútua em sociedade. No que toca à educação, a ética do cuidado pode e deve amparar o quadro que se está formando para os próximos anos, pois, como podemos observar nas grandes mídias, o isolamento social tem efeitos não apenas em relação ao emprego, ao relacionamento familiar e à aprendizagem dos estudantes, mas também provoca efeitos psicológicos e de convívio social em longo prazo. Com o retorno das aulas presenciais, teremos uma reconfiguração dos nossos laços sociais e estudantes marcados por relações

19 Ou seja, como Carvalho (2013) afirma: “(..) sendo um professor justo que ensinamos a nossos alunos o valor e o princípio da justiça; sendo respeitosos e exigindo que eles também o sejam, ensinamos o respeito não como um conceito, mas como um princípio que gera disposições e se manifesta em ações" (p. 55). 
do tipo estritamente familiar. Devemos estar atentos a como podemos amparar esse retorno que não significará uma volta ao contexto escolar apenas, mas uma nova experiência de estranhamento e acoIhimento. Uma vez mais, a ética do cuidado e sua dimensão solidária podem se tornar presentes. A base sólida e consistente que possibilitará um cuidado de si, dos outros, bem como das coisas e do mundo.

Frente a tentativas de reformulação da escola em um ambiente cívico-militar e à série de ataques às disciplinas de filosofia e sociologia na educação em geral, a ética do cuidado na educação propõe-se como uma alternativa para o momento atual da educação brasileira, a qual anseia por uma mudança em seu ethos escolar, isto é, exige uma maior contextualização dos saberes para a apreensão de novos e complexos aspectos da realidade. Com isso, podemos concluir: como defender a presença da filosofia na educação básica? Pela transversalidade, a formação pessoal e a consciência da sua função formativa. Onde encontrar esse amparo teórico? A despeito de algumas alternativas corretamente plausíveis, optamos aqui pela ética do cuidado.

\section{REFERÊNCIAS}

CARVALHO, José Sérgio. Reflexões sobre educação, formação e esfera pública. Porto Alegre: Penso, 2013. GALLO, Sílvio; GRISOTTO, Américo. A transversalidade da ética na escola. In: Revista de Educação. Ano 31 - n. 125 - Outubro/Dezembro de 2002.

HEGEL, Georg Wilhelm Friedrich. Grundlinien der Philosophie des Rechts. Suhrkamp Verlag Frankfurt am Main, 1970.

HELD, Virginia. Feminist transformations of moral theory. Philosophy and Phenomenological Research, v. 50, Supplement (Autumn. 1990), p. 321-344.

MISSAGIA, Juliana. Ética do cuidado: duas formulações e suas objeções. Blogs de Ciência da Universidade Estadual de Campinas: Mulheres na Filosofia, v. 6 n. 3, 2020, p. 55-67.

PEREIRA, Fábio Gai. Ética: perspectivas sobre o seu ensino. In: SPINELLI, Priscilla Tesch [et al.] (orgs.). Diálogos com a escola: experiências em formação continuada em filosofia na UFRGS I. Porto Alegre: Evangraf, 2013.

PIAGET, Jean. Para onde vai a educação?. Tradução de Ivette Braga. Rio de Janeiro: José Olympio, 2011. ROCHA, Ronai Pires da. Ensino de filosofia e currículo. 2. ed. Santa Maria: Ed. da UFSM, 2015.

ROCHA, Ronai Pires da. Escola partida: ética e política na sala de aula. São Paulo: Contexto, 2020.

ROCHA, Ronai Pires da. Quando ninguém educa: questionando Paulo Freire. São Paulo: Contexto, 2017.

SOPHOCLES. The Antigone of Sophocles. Ed. with introduction and notes by Sir Richard Jebb. Cambridge: Cambridge University Press, 1891. 
